\title{
Recycling Urine for Hydrogen Production in a Microbial Electrolysis Cell (MEC) System Using a Novel Mos2 Nano Carbon Coated Electrode
}

\author{
Woo Hyoung Lee, ${ }^{1, *}$ Jae-Hoon Hwang, ${ }^{1}$ Saisaban Fahad, ${ }^{2}$ Hodon Ryu, ${ }^{3}$ Kelsey L. Rodriguez, ${ }^{1}$ Jorge Santo \\ Domingo, ${ }^{3}$ Akihiro Kushima, ${ }^{2}, 4$ \\ ${ }^{1}$ Department of Civil, Environmental, and Construction Engineering, University of Central Florida, \\ Orlando, FL 32816, USA \\ ${ }^{2}$ Department of Materials Science and Engineering, University of Central Florida, \\ Orlando, FL 32816, USA \\ ${ }^{3}$ United States Environmental Protection Agency, Office of Research and Development, \\ 26 W. Martin Luther King Drive, Cincinnati, OH 45268, USA \\ ${ }^{4}$ Advanced Materials Processing and Analysis Center, and NanoScience Technology Center, University of Central Florida, \\ Orlando, FL 32816, USA
}

\begin{abstract}
Microbial electrolysis cells (MECs) can produce hydrogen gas from organic compounds in an energy-efficient way by taking advantage of the potential generated by microorganisms. Human urine has been successfully used as an electrolyte and organic substrate in bioelectrochemical systems (BESs) mainly due of its unique properties such as high conductivity in a solution which can reduce the ohmic losses and improve BES output. However, the hydrogen evolution reaction (HER) in MECs using urine is a slow process and thus requires the development of catalysts in a cathode. In this study, a novel molybdenum disulfide $\left(\mathrm{MoS}_{2}\right)$ nano-carbon (NC) coated cathode was developed for urine treatment and improved hydrogen production in a microbial electrolysis cell (MEC) with different experiments ranging from 2-6 times diluted urine. $\mathrm{MoS}_{2}$ nanoparticles were electrodeposited on the NC coated cathodes with $-100,-150$ and $-200 \mu \mathrm{A} \mathrm{cm}^{-2}$ and their performance was compared to NC only and carbon cloth (CC) cathodes in the MEC. The $\mathrm{MoS}_{2}-\mathrm{NC} 200$ (electrodeposition at $-200 \mu \mathrm{A} \mathrm{cm} \mathrm{cm}^{-2}$ ) cathode produced slightly higher hydrogen rates $\left(0.061 \pm 0.004 \mathrm{~m}^{3} \mathrm{H}_{2} \mathrm{~m}^{-3} \mathrm{MEC} \mathrm{d} \mathrm{d}^{-1}\right)$ compared to $\mathrm{MoS}_{2}-\mathrm{NC} 100(0.058 \pm$ $0.002 \mathrm{~m}^{3} \mathrm{H}_{2} \mathrm{~m}^{-3}$ MEC d $\left.\mathrm{d}^{-1}\right)$ under two times diluted urine. The $\mathrm{MoS}_{2}-\mathrm{NC} 200$ cathode had significantly higher $(\sim 31 \%)$ hydrogen production than the carbon cloth (CC) cathode with the same dilution of urine. The reproducibility tests of the $\mathrm{MoS}_{2}$-NC cathodes after a short MEC operation period ( $\sim 5$ cycles) showed a stable $\mathrm{MoS}_{2}$ coating on the NC cathodes. Maximum ammonia-nitrogen $\left(\mathrm{NH}_{3}-\mathrm{N}\right)$ and phosphorus $\left(\mathrm{PO}_{4}{ }^{3-}-\mathrm{P}\right)$ removal with varying dilution factors was $68.7 \pm 0.1 \%$ and $98.6 \pm 0.3 \%$, respectively. Some of the exoelectrogenic bacteria were identified as members of the Clostridia and Bacteroidetes taxa. The newly fabricated $\mathrm{MoS}_{2}-\mathrm{NC}$ cathode will be a suitable strategy for microbial acclimation to urine in a MEC for a novel biotransformation process within the water-energy nexus.
\end{abstract}

Keywords: Ammonia-nitrogen, electrodeposition, $\mathrm{MEC}, \mathrm{MoS}_{2}-\mathrm{NC}$ cathode, urine 